\title{
The Theory and Practice of the Six-Step Method in EFL and Its Transferability to Engineering Programmes
}

\author{
Berrington X. S. Ntombela ${ }^{1}$ \\ ${ }^{1}$ College of Education, English Department, SABIS® University of Erbil, Erbil, Kurdistan, Iraq \\ Correspondence: Berrington X.S. Ntombela, SABIS $\circledR^{-}$University of Erbil, 40 Meter Street, Italian City, Behind \\ Erbil Rotana Hotel, Erbil, Kurdistan, Iraq. Tel: 964-750-716-9400. E-mail: zanibaz@yahoo.com
}

Received: January 24, 2013 Accepted: February 10, 2013 Online Published: March 10, 2013

doi:10.5539/elt.v6n4p80 URL: http://dx.doi.org/10.5539/elt.v6n4p80

\begin{abstract}
This paper outlines the theory of the six-step method developed by personnel in the Language and Learning department at Caledonian College of Engineering, Oman. The paper further illustrates the application of this method in teaching Project, Listening, Reading, Writing, and Speaking \& Debate at Foundation level. The assumption in applying the six-step method at Foundation level is that, after repeated exposure, learners should be able to apply it in their engineering studies. The paper therefore discusses the transferability of this method both as a teaching and as a learning approach. Findings indicate that the six-step method in EFL context expects more from learners whose linguistic level is lower than it should be due to insufficient exposure to the target language. That is, the method works much better on the application level, where learners are expected to work independently (with the teacher taking a 'backseat') to accomplish a given task. Notwithstanding, the method encourages and fosters independent learning and the acquisition of soft skills. Furthermore, findings reveal that the transferability of the method to engineering programmes as a learning approach leans heavily on its application as a teaching approach.
\end{abstract}

Keywords: six-step method, soft skills, EFL

\section{Introduction}

The present study is based in the engineering college in Oman which in addition to regular engineering programmes, offers a Foundation Programme; a common feature in the Gulf region. The Foundation Programme is solely designed to bridge the gap between secondary school and tertiary education and is compulsory for all students wishing to enroll for Omani degree programmes (Oman Academic Standards for General Foundation Programmes (OAC for GFP), 2007; Sivaraman et al, 2012). At first the programme focused on English because most students come to tertiary education from a background where most subjects are taught in Arabic. However, later on Mathematics, IT Skills and General Study Skills were added (OAC for GFP, 2007). Study Skills, however, could either be offered separately or could be embedded in other subjects.

As already mentioned that most students enrolling for a Foundation Programme come from a predominantly Arabic background, they mostly speak Arabic both in class and outside the classroom (Ntombela \& Dube, 2010). This phenomenon is very common in EFL context where students mostly speak the same language, which poses challenges in practising English as a target language. That is, students find it logically practical to use the language that is immediately available. This calls for innovative approaches in which the least available time for practising English is maximized. In fact, English Language Teaching presently fosters methodologies that seek to improve students' communicative competence. Likewise, the institution where the study was conducted has developed a six-step method in its Language \& Learning module with the hope that this method can be transferred to other programmes in engineering. It should be pointed out here that the EFL syllabus mainly consists of four skills: Reading, Writing, Listening, and Speaking (which are communication skills) as opposed to the content nature of engineering modules. That is one of the reasons why some approaches in teaching a skills-based subject differ from those of a content-based one.In other words, most content subjects like physics, engineering, etc. teach facts, whilst language teaches communication skills which whilst being the content are also the medium through which that content is transmitted which transmission is in turn the focus of learning (Borg, 2006).

The thought of the transferability of six-step method to engineering programmes is based on the explanation that 
the six-step method is not to be regarded as a teaching approach, but a learning approach - used by students to respond to any academic task or even to ordinary everyday tasks (Ntombela, 2011); notwithstanding, a need has been identified to train teachers of other subjects so that they can use the method (Caledonian College of Engineering, 2010). Suffice now to explain what the six-step method entails.

\section{The Six-Step Method}

The six-step method literally consists of six steps that are adapted depending on the course that is being offered. For instance, when teaching Project, Academic Writing and Speaking \& Debate, six-step method is realized as the Blank Page Method (BPM). When teaching Reading the same method is realized as Multiple Page Method (MPM), whilst it is realized as Listening Proactive Method (LPM) in Listening. In Writing \& Reading Practical, the six-step method combines the BPM used in Writing and MPM used in Reading to form a Combined Page Method (CPM). In fact, the six steps can be summarized into think, research, plan, execute, review, and present. One important element to be stressed here is that the six-step method applies all the steps in the same sequential order.

\section{$2.1 B P M$}

The BPM, as mentioned, is followed when teaching Project, Academic Writing and Speaking and Debate. In Project, students need to think about the project they are going to do, which can either be a Staff Portrait Gallery where they interview four members of college staff; Pamphlet based on the college theme where students carry out a survey; or Class Magazine which combines the interview and survey skills they had gained. After recording their ideas in a spider diagram, they need to consult other sources in order to get more information, which is a research step. The information they had gathered is then organized according to the plan given in the remit. In other words they need to plan how materials they have gathered will be put together. Writing stage is when they put into action the plan, by for instance writing up survey results or summaries of interviews. They need to correct own writing first, ascertaining that grammar elements that were covered, such as polite forms, simple present etc. are correct and thereafter turn the piece to the teacher for further editing. The last step is to make sure that the work they are going to present is of acceptable standard, is attractive and eye-catching.

In Academic Writing the main assignment is the 1500 words essay that they need to write. However, it is not necessarily the essay that is the focus of the course than the steps they go through in producing it. They therefore need to go through the six steps starting with brainstorming where they brainstorm the topic they are going to write about, recording initial ideas about that topic and putting those ideas into headings that represent the structure of the essay. In fact, they are taught a formula for thinking which incidentally consists of six steps. Once brainstorming is done they need to find extra information from at least one book, one journal, and two Internet articles. Most importantly they need to write information in note-form mostly in their own words, putting own ideas in square brackets and a few verbatim quotes in quotation marks. After research students must organize information gathered during the brainstorming and research into a plan that represents the structure of a discursive essay. That is, students must organize all the information into introduction, counter argument, argument, and conclusion. All they have to do is slot the information into these headings by copying or cutting and pasting it from research. Writing, which is the next step, should be easier once they have the plan. However, they now need to expand the notes made during brainstorming and research into a coherent piece of writing making sure that their own voice is maintained. During the writing stage they should also attend to specific conventions such as avoiding writing in the first person, avoiding split infinitives and double negatives. The focus of the editing stage is on referencing. Students should make sure that all materials used from their research are appropriately referenced following Harvard system of referencing as adopted in the institution. The final stage is presenting where students must follow a prescribed structure of presenting the essay including font types, colours and sizes for various sections of the essay.

In a Speaking \& Debate component, brainstorming, the first stage of the BPM expects students to "think about both sides of the issue as widely as possible" using own experiences (Walker, 2009a, p. 19). That is, as students are teamed into opposing teams, each member of the team must not only concern him/herself with information that pertains to own team but must be conversant with arguments that counter own team's. As part of preparing for the debate students need to devote a lot of their time researching information about issues at hand in the library, Internet etc. When they have collected enough information they need to arrange that information into points. This happens during the planning stage where reasons and examples for every point they have generated are clearly arranged "for both sides of the debate" (Walker, loc. cit.). However, during the writing stage students must write arguments pertaining to their side in the language of the debate. The editing stage gives students a chance to polish up their work, correcting and refining their points. The final step of the BPM does not actually 
occur during the debate, but is a form of rehearsal where according to Walker's (loc. cit.) advice, students individually "practice using all the 'tricks' of delivery in front of the mirror."

\subsection{MPM}

The Multiple Page Method is used when teaching Reading. The six steps involved are: thinking, research, planning, reading, comprehension, and presentation. When students are presented with a reading text, they need to ask themselves several questions, which will facilitate thinking. The first question pertainsto what the article is about. To answer this question they need to read the title, scan subtitles or look at pictures if there are any. This will help them guess what the text will be about. They also need to question themselves where they need to start. This will help them think about what they already know about the subject either from own experiences or what they learnt from books. The other question pertains to the reason for reading the article. Depending on the instructions, it might be, for instance, that they have to answer comprehension questions; on the whole, considering this question will dictate the appropriate reading strategy/skill. Thus, the relevant reading strategy will be determined by what they need to do after reading. For instance, if they "have to look for specific information" they only have "to scan the appropriate paragraph", but if they "have to answer comprehension questions", they must skim through the whole text (Walker, 2009b, p. 18). Walker (loc. cit.) emphasizes that all the thinking should be recorded in a spider diagram including information they already know and brief notes about the appropriate reading strategy they feel must be adopted.

The challenge that students normally face with reading is new vocabulary, which frustrates their understanding of the text. Walker (loc. cit.) advises that students skim through the text quickly, underlining words they do not understand only if they are repeated. She (loc. cit.) suggests that students must pay close attention to introduction (or first paragraph) and conclusion (or last paragraph), ignoring those words they do not understand if they occur only once in the entire text. Once they have underlined words they do not understand, they must guess the meaning by using strategies such as breaking the word down into smaller parts, checking with friends, and only resorting to a dictionary if all fails. All this represents the planning step in MPM.

During the research step of the MPM, students would have underlined the important sections as suggested by post-reading tasks, now they need to plan what they will do with sections that are not relevant. In order to stay focused, they must literally cross out irrelevant sections. Then, they need to consider the amount of time they have to read the article. Walker (op. cit.) strongly advises against starting reading without setting a time limit. Once they have determined the time available, they must divide the text into sections, working out how much time they will spend in each section. They must learn to be disciplined enough to stop reading the section if they do not finish it in allocated time.

When students get into the reading stage, they have to consider what makes their brains active while reading. They are advised to guess what the author is likely to say, which will create anticipation; but also they need to question what the author is saying as they read (Walker op. cit.). They need to do all this within the time allotted for that section. As they read they should have the purpose in mind, which by underlining main ideas must help them remember important parts. In addition, since they are engaged in questioning what the author is saying, it will help them to have a separate sheet of paper where they could record brief notes in own words. The emphasis placed in reading stage is that students need not understand each and every word, but must concentrate on main ideas; however, they must have post-reading tasks in mind, which will inform not only the skills to be used, but also the information they must look for.

The fifth step in the MPM is comprehension, which on the outset must answer the question of how students might understand what they have just read. Walker (op. cit.) opines that students stand to benefit if they identify the structure of the article they have read (especially if there are no subtitles). She (ibid) therefore advises that students label parts of the article with appropriate subtitles based on the content of the sections, identifying such parts as introduction and conclusion. Students must also reread the notes and see if they could answer the questions without going back to the article. They will also need to ask themselves what they can learn from the article and whether they can disagree with the author. This is important because the kind of article, whether factual "like a chapter in a textbook", or discursive which invites the reader's opinion determines the response the reader (student) needs to give (Walker, 2009b, p. 20). At times students are given more than one article on a similar topic, so they need to summarise similarities and differences of these articles.

The final step in MPM is presentation where students should be concerned with what they might do with the article they have comprehended. This is the stage for post reading tasks. Students therefore are advised to timetable post reading tasks based on the available time. They need not go back to the entire text, but will need to scan the paragraph(s) with essential information. The notes they took should provide most of the information. 


\section{$2.3 C P M$}

The Combined Page Method (CPM), as the term suggests, combines the MPM and BPM. That is, students have to complete a given task within a given time, say 60 minutes. This is meant to train them for exam conditions. The course that uses CPM is Writing \& Reading Practical, where students are given reading texts from which they need to make notes, write a summary, or write a timed-essay. The time for doing this is normally split into thirty minutes for reading the text (using the MPM) and thirty minutes for writing (using the BPM).

The thinking stage in CPM expects students to read the title together with any instructions about the timed assignment. Reading the title and subtitles of the text will help them guess the content. If there are pictures, they may use them to consider whether there is anything they already know about the subject. They are also expected to use the spider diagram in brainstorming the subject, and since they are expected to answer the question, they may also write a 'mini' answer based on their own opinion (Walker, 2009c).

The second step in CPM is research. Here students must consider the amount of time they have to read the article. They therefore need to quickly skim the text, crossing out sections that will not help in answering the question. The remaining sections should be allotted time after which they must start reading those sections bearing in mind the amount of time allotted for each. As they read they are advised to underline ideas that are essential in answering the question. Then the underlined ideas should be lifted from the text and written in own words in note-form. As they write notes, perhaps in their notebooks, they are advised to copy the title, and "author of the article, and page numbers by the side of each note" (Walker, ibid, 4). Thereafter, students must work out the structure of the article, labeling such parts as introduction and conclusion. They must also decide whether the article is a statement of fact or whether it is inviting a reader's opinion to either "agree or disagree with the author" (Walker, loc. cit.).

During the planning stage, students must revisit their spider diagrams made during the thinking stage and cross out any ideas that are no longer relevant, but must also add any points they have learnt from the article. Since the timed-essays in Writing \& Reading Practical course follow the same pattern as in Academic Writing where students must write a 1500 word essay of a discursive type, during the planning stage they need to number the points in their spider diagrams according to whether they belong to introduction, counter-argument, argument, and conclusion. They do so using the notes made from reading the article (Walker, loc. cit.). Their plan should also include reasons and examples that they will use in supporting arguments and counter-arguments. In other words, the plan will have subtitles: introduction, counter-argument, argument, and conclusion, and another column where numbers representing reasons and examples are jotted correspondingly with counter-argument and argument.

The fourth step of CPM is writing where students must follow the plan to the letter. The most important part is that they should exclusively write in their own words, but if they have to quote verbatim, they need "to use quotation marks... followed by the author's name, date and page number in brackets" (Walker, ibid, 5).

Editing step requires students to check whether they have accurately represented the information they have quoted verbatim. They also need to check for punctuation, spelling and grammar correctness. The other part they must ascertain is the legibility of their handwriting.

The last step of the CPM is concerned with how presentable the piece of work is. In that respect students need to make sure that they have written a title, their name and the date. Paragraph breaks should be visible by either leaving a line or by indentation. Corrections made during editing stage should be neat and tidy so that the writing is legible.

\section{$2.4 L P M$}

The Listening Proactive Method (LPM) used for the Listening course operates under the premise that students need to be active listeners rather than passive ones. Like the BPM, MPM, and CPM, this method has six steps. It must be mentioned that since the institution where this method is used is an engineering one, where courses are predominantly offered in the form of lectures, the LPM is designed to help students benefit from lectures and thus aid their learning experience. Therefore, most listening materials are in the form video-recorded lectures.

The first step in LPM is thinking about what the lecture will be about. Here students can ask the teacher, consult the course guide, or by simply using the title. They also need to consider what they already know about the subject by brainstorming using a spider diagram. They also need to think about whether they have any personal experience about the subject.

The research step of the LPM requires students to ask themselves the reason why they must listen to the lecture. This means they have to know whether they will be required to do something after listening, say writing a 
summary, answering comprehension questions, etc. Before coming to class students need to have previewed as much as possible, which means they need to check with the teacher who could help them by either providing reading material or direct them towhere they could access materials related to the topic. Walker, (2009d) believes that the more students bring something to the listening, the more they will get out of it. In addition to why they need to listen to the lecture, students need to further ask how they should listen to the passage. For instance, if they have to answer comprehension questions, they only need to concentrate on the gist, or if they need specific information they must look for key words. That is, the manner in which listening would be approached depends on post-listening tasks.

The third step of the LPM concerns the amount of time that students must spend listening. This is especially vital when they are going to listen to the lecture because they may be easily put off if they suddenly find themselves having to spend say 45 minutes whilst they had tuned their minds for a 20 minute lecture. They should therefore enquire from the teacher how long the listening is going to be so that they can concentrate better (Walker, ibid, 23). Furthermore, concern about time should extend to post-listening tasks. They need to know how much available time they have so that they can time post-listening tasks.

Because LPM is mainly concerned with active listening, during the actual listening the main question is how students could make their brains active. It is expected that since students have spent a lot of time preparing for the listening, they expect what to hear, but Walker (loc. cit.) emphasizes that they need to contrast what they expect with what they will actually hear. They can do that by constantly asking themselves questions as they listen and by creating mental pictures of what the speaker is saying. The other most important aspect is how they will remember the parts that are important. The advice given to students is that they should write notes of the main ideas as they listen, which main ideas must correspond with post-listening tasks. Walker (2009d) strongly believes that most teachers tell students what the lecture will be about in the introduction and "repeat that information in the conclusion" (p. 23) which justifies her advice that students should therefore pay closer attention to those parts.

The fifth step of the LPM is comprehension. Students need to know how they could understand what they have heard. To better their understanding they need to go back to the main points of the lecture and concentrate more on what they understood than on what they did not. They will also make use of the notes for answering comprehension questions or writing a summary. Walker, (2009d) further suggests that students consider whether the type of lecture is of a factual kind or whether it invites them to express own opinions by way of agreeing or disagreeing.

The last step is presentation where students need to come up with a timetable for completing post-listening tasks and stick to it. However, since LPM is for listening, if they have to write a summary or any piece of writing, Walker (op. cit.) advises that they follow BPM to complete that writing task.

\section{Application of the Six-Step Method}

As mentioned, BPM is adopted when teaching Academic Writing, Project, and Speaking \& Debate. In Academic Writing the application of the method is more explicit as can be seen in the breakdown of the units and contents in Table 1 below.

Table 1. Academic Writing

\begin{tabular}{ll}
\hline Unit & Description \\
1 & Introduction \\
2 & Writing a summary \\
4 & Writing a Timed essay \\
5 & Brainstorm for the final essay \\
6 & Research for the final essay \\
7 & Plan for the final essay \\
8 & Write the First draft of the final essay \\
9 & Edit the first draft of the final essay \\
10 & Present the final essay \\
\hline
\end{tabular}

A similar pattern can also be observed with Project as demonstrated in Table 2 below. 
Table 2. Project

\begin{tabular}{ll}
\hline Unit & Contents \\
1 & Need for English as a student \\
2 & English in the engineering profession \\
& Defining the term 'Project' \\
& Building and organizing teams \\
3 & Method for undertaking a project \\
& Keeping to a deadline \\
4 & Brainstorming a task \\
& Asking right questions \\
6 & Making a wall presentation \\
& Conducting research \\
7 & Writing a questionnaire \\
& Presenting data \\
& Making a technical pamphlet \\
9 & The point of magazines \\
& How magazines are made \\
10 & Responding to the remit \\
& Planning the magazine \\
\hline
\end{tabular}

The six steps: think, research, plan, write, edit, present can be traced across the units in both components. It should also be pointed out that in Project students are engaged in completing three projects, each of which employs all the steps of the BPM. In Speaking \& Debate, however, the application is not as explicit as it is largely left with the students to apply it. There is also no explicit mechanism to measure whether students are applying the method because its application occurs during the preparation stages, which are normally carried out outside the classroom. Nonetheless, Walker (2009a) advises that students be divided into Team A and B, where all students in each team are expected to brainstorm, research, plan and write a speech for the debate.

At the beginning of the Reading course, students are given the theory of MPM, which must be applied throughout the duration of the semester. Walker (2009b) highlights that students need to grasp the MPM because they will be assessed on their understanding of the method and its application "to an article during their reading exams" (p. 22). However, the actual delivery of the course does not explicitly incorporate all the elements of MPM. For instance, a typical Reading lesson begins with students either discussing statements related to the topic, justifying why they agree or disagree with those statements; or going through vocabulary items that are the focus of the text. The rest of the activities include matching tasks, gap fills, completing flow charts or writing short paragraphs. In real practice therefore, students normally do not apply the theory of MPM, but simple complete the tasks as presented to them.

Similarly, the LPM is not explicitly applied in the Listening course. The main focus on Listening is on note taking. Students are given a structure that shows headings, sub-headings, and main ideas, which they use to practise taking notes throughout the course of the semester. A typical lesson would thus begin with students watching the video and slotting information into appropriate places, like in headings, sub-headings, or main ideas. They may also be asked to watch video and record the gist information. Like MPM's application in the Reading course, it is not easy to point where students practice LPM during Listening, i.e. the six steps are not immediately traceable.

With Writing \& Reading Practical, the input on the method is at the beginning of the course where students are taught how to apply CPM in writing a summary and another one before they begin assignments on note taking. Students are then left on their own to practise the method, needless to say that students simply follow individual approaches in responding to the remit. In total students should complete ten assignments in which eight should be peer-checked and the best two given to the teacher for marking. Table 3 below shows the course content with different assignments that students must write. Suffice to mention that neither marking guides for all the assignments consider the application of CPM as it is the case with BPM in Project and Academic Writing. 
Table 3. Writing \& Reading Practical

\begin{tabular}{lll}
\hline Unit & Assignment & Title \\
Preface 1 & Input / Summary & Learning about Engineering \\
Preface 2 & Introduction & Weekly Practical \\
1 & Summary & Structural Engineering \\
2 & Summary & Computer Aided Design \\
3 & Summary & What is Mechatronics \\
4 & Input / Note taking & Desalination \\
5 & Note taking & Waste Management \\
6 & Note taking & Health \& Safety in the Workplace \\
7 & Note taking & WAN \& LAN \\
8 & Essay & Alternative Sources of energy \\
9 & Essay & Debating Engineering \\
10 & Essay & Robots in Industry \\
11 & Essay & Global Warming \\
\hline
\end{tabular}

\section{Transferability of the Six-Step Method to Engineering Programmes}

One observable benefit for the six-step method is that it enables students to acquire academic and study skills. In Project, for instance, following the BPM, students work in teams to accomplish given tasks, which, as reported by Ntombela (2010) promotes such skills as teamwork, time-management, and critical thinking. Similarly, BPM as followed in Academic Writing promotes critical thinking, research skills, and planning (i.e. time-management) (Ntombela, 2011). Furthermore, Yusuff and Ntombela (2012) argue that LPM is beneficial in the acquisition of skills such as teamwork, note-taking, and research skills. These skills are arguably transferable to other subjects especially in engineering.

Nonetheless, Ntombela (2010) argues that BPM as used in the Project component approximates Project-based Learning approach with the main difference that Project is not an approach, but a subject on its own. The same argument also applies to the case of Academic Writing where BPM is seen as another expression of process writing with such stages as "pre-writing, editing, redrafting, and publishing" (Harmer, 2006, p. 257); or "generating, focusing, structuring, drafting, evaluating, and reviewing" (White \& Arndt, 1991, p. 6). However, Ntombela (2011) argues that the BPM as applied in Academic Writing does not successfully develop students' writing abilities. He (ibid) bases his argument on the fact that the analysis of the essays written by students following the BPM did not show improvement in writing skill as opposed to other aspects like thinking, researching, and planning. Interestingly, Yusuff and Ntombela (2012) conclude that LPM is only but a set of good strategies for teaching Listening as suggested by Wilson (2009). This seems to echo the conclusion drawn by a panel that reviewed the Foundation Programme in the institution where study was conducted where they report that the six-step method poses itself as a radical approach but is essentially the imprint of "contemporary learner-centred, discovery-oriented EFL" approach, which is also task-based as it allows students to engage in technical activities that help them improve their language skills (Review, 2010, p. 3-4).

With the exception of Project, all components offered through the six-step method are the core elements of a typical EFL syllabus, viz. Reading, Writing, Listening, and Speaking. On the contrary, engineering programmes offer content-based subjects where the challenge is how to break from traditional deductive approaches that are considered teacher-centred, to contemporary inductive learner-centred approaches (Felder \& Brent, 2004). The incorporation of Project as a component in the Foundation Programme had two main reasons. First, the Industrial Interaction Group (IIG) had reported that graduates produced by the institution where the study is based were lacking soft skills and Ntombela (2010) argued that Project component facilitates the acquisition of these skills. The second reason, pinned to the first one, is that when students have been armored with these skills, they will be more likely to carry them to their engineering subjects and probably to future workplaces.

The pressing question now pertains to the transferability of the six-step method to engineering programmes. It has already been mentioned that the application of this method in Reading, Listening, Writing \& Reading Practical, and Speaking \& Debate is not satisfactory. Perhaps the difficulty in applying this method should, among other things, be blamed to the assumption that students fail only by virtue of not following a method. Unfortunately, the reality in EFL context points to the fact that students need more than a method, but competence in the target language which will make it easier for them to apply the theories on what they understand. In other words, students and, to a certain extent, teachers need to overcome linguistic hurdles before 
they can successfully apply methods that lean on such competence.

The transferability of six-step method seemingly cannot occur automatically. That is, as Murphy (2009) in Ntombela (2010) asserts, the six-step method needs to be explicitly highlighted in each subject if it is to be applied. In other words, both students and teachers are likely to view it as only applicable to the subject where it explicitly forms part of course delivery. This should be expected as it has already been presented that the six-step method is but only an adaptation of the contemporarylearner-centred, task-based methods used in EFL.

\section{Conclusion}

The six-step method poses itself as a radical novel approach in EFL. Undoubtedly, there are observable benefits in using the method, such as facilitating soft skills acquisition. These skills that are not only required for successful academic achievement, but for employment as well. In the institution where the study was conducted, the soft skills address the concern raised by the Industrial Interaction Group as stated above.

Nonetheless, most benefits of the method seem to be lost in theory, as they do not immediately find application. This has been reported in the case of MPM, CPM and LPM. The main reason behind this failure can be attributed to the fact that MPM, CPM and LPM are presented theoretically at the beginning of the courses where they are to be applied, but are not explicitly highlighted in the delivery of the course content.

The transferability of the six-step method to engineering programmes as envisaged by the institution does not seem viable for various reasons. First, the method does not have full application in all the modules in language modules where it is theoretically presented. Although its application to other non-linguistic components is believed to be achievable with repeated exposure, such exposure is only visible in the Project and Academic Writing because the method is built in the course; for other components like Reading, Listening, Writing \& Reading Practical, and Speaking \& Debate the method is not immediately applied, which results in limited exposure to the method. Second, the six-step method, as argued, is a shadow of the contemporary learner-centred approaches in EFL. That is, EFL methodologies seek to facilitate the speed with which students acquire competence in the target language. Therefore, the logic of transferring a method that predominantly addresses communication skills to the context where the focus is the content or the transmission of facts is questionable. Nevertheless, the six-step method or its adaptation could be embedded in engineering programmes with an aim of promoting soft skills.

Furthermore, one aspect that may improve the applicability of the six-step method is the reduction of its rigidity. For instance, the process approach in writing from which BPM as applied in Academic Writing is adapted acknowledges the complex, cyclical and fluid nature of the process of writing (Harmer, 2006 and White \& Arndt, 1991). On the contrary, six-step method expects students to rigidly apply it in the same sequence, which runs contrary to what writers go through when writing. Making the six-step method more flexible will therefore render it user-friendly.

\section{References}

Borg, S. (2006). The distinctive characteristics of foreign language teachers. Language Teaching Research, 10(1), 3-31. http://dx.doi.org/10.1191/13621688061r182oa

Caledonian College of Engineering. (2010). Overview of the Caledonian College of Engineering Foundation Programme, External Review 17-18 Oct. 2010. Muscat: Caledonian College of Engineering.

Felder, R. M., \& Brent, R. (2004). The ABC's of engineering education: ABET, Blooms taxonomy, Cooperative learning, and so on. Proceedings of the 2004 American Society for Engineering Education Annual Conference \& Exposition. Retrieved July 28, 2010, from http://www4.ncsu.edu/unity/lockers/users/f/felder/public/papers/ASEE04(ABCs).pdf

Harmer, J. (2006). The Practice of English Language Teaching. Essex: Longman.

Ntombela, B. (2010). Acquisition of Soft Skills. Proceedings of The Asian Conference on Arts and Humanities (pp. 597-608). Osaka: IAFOR.

Ntombela, B. X. S., \& Dube, E. N. (2010). L1 in EFL context in Oman colleges. In McBeath, N. (Ed), Proceedings of The Tenth Annual ELT Conference Current Perspectives in ELT: New Methodologies, Research, and Best Practices (pp. 76-88). Muscat: Sultan Qaboos University.

Ntombela, B. X. S. (2011). English Language Teaching and the Promotion of Academic Ethics. In J. Mukundan, V. Nimehchisalem, S. Menon, N. Jin Yu, N. Roslim, A. L. C Har, .... A. Philip (Eds.), ELT Matters 5: Developments in English language learning and teaching (pp. 197-209). Serdang: Universiti Putra Malaysia. 
Oman Academic Standards for General Foundation Programs. (2007). Retrieved August 28, 2009, from http://www.oac.gov.om/files/assurance/draft_standards/gfp_standards_v4.pdf

Review of the Foundation Programme at the Caledonian College of Engineering, Muscat, Oman, 2010. October 17-18, 2010.

Sivaraman, I., Al Bulushi, A. H. M., Rao, D. H., \& Rizwan, S. M. (2012). Entry into engineering programs performance comparison of foundation students with direct entry students. Paper presented at Oman Quality Network for Higher Education Regional Conference, Muscat, 20-21 February 2012.

Walker, J. (2009a). Language\& Learning 2: Debate Preface 1. Muscat: Caledonian College of Engineering.

Walker, J. (2009b). Language \& Learning 2: Reading Component Preface. Muscat: Caledonian College of Engineering.

Walker, J. (2009c). Language \& Learning 2: Writing \& Reading Practical Preface. Muscat: Caledonian College of Engineering.

Walker, J. (2009d). Language \& Learning 2: Listening Preface. Muscat: Caledonian College of Engineering.

Wilson, J. J. (2010). How to teach listening. Essex: Pearson Longman.

White, R., \& Arndt, V. (1991). Process Writing. Essex: Longman.

Yousuf, N., \& Ntombela, B. X. S. (2012). Does Listening Proactive Method Enhance Study Skills? Paper presented in the $12^{\text {th }}$ Annual Conference: Quality in ELT - Raising Pedagogical Standards. April 18-19, 2012. Sultan Qaboos University, Muscat. 